\title{
Circadian Rhythm Sleep Disorder among Nurses in Emergency Department: A Systematic Review
}

\author{
Arief Wahyudi Jadmiko'), Rieh Firdausi²) \\ ${ }^{1)}$ Study Program of Nursing, Faculty of Health Sciences, \\ Universitas Pembangunan Nasional Jakarta \\ 2)Study Program of Nursing, Faculty of Health Sciences, \\ Universitas Muhammadiyah Surakarta
}

\begin{abstract}
Background: Circadian Rhythm Sleep Disorders (CRSD) is a sleep pattern disorder that can be caused by a shift work system, especially the night shift. This disorder can cause various cardiovascular diseases, psychological, decreased concentration, even Alzheimer's. Some professions that demand high precision such as nurses who work with night shifts in the Emergency Room are very vulnerable to CRSD and if not handled, it can lead to work negligence. The purpose of this review is to review CRSD due to work shifts, possible risks to the ED nurse and how to overcome them.

Subjects and Method: This article uses CRSD-related reviews published from 2000-2018 from various databases: PubMed, PMC Central and Elsevier open-access. The search was conducted on 1-14 July 2018 with keywords: "Circadian Rhythm Sleep Disorders", "treatment AND CRSD", "the effect of CRSD", "CRSD AND nursing, and" CRSD in night workers ".

Results: Based on the 20 articles reviewed, CRSD is a sleep pattern disorder that can be caused by endogenous factors and exogenous factors. One exogenous factor is a disturbance due to working time with the shift work disorders (SWD) system. There are several ways to overcome CRSD due to working hours, including: taking a nap before work, modifying the environment by avoiding light if going to sleep, but approaching light if you have to wake up, resetting your sleep schedule, and giving melatonin.

Conclusions: CRSD due to work disorders is called SWD which can be overcome by rearranging sleep, modifying the environment to fit the circadian rhythm, and consuming melatonin if needed.
\end{abstract}

Keywords: Circadian rhythm sleep disorders, shift work disorders, nurses

\section{Correspondence:}

Arief Wahyudi Jadmiko. Study Program of Nursing, Faculty of Health Sciences, Universitas Pembangunan Nasional Jakarta. Email: awjadmiko@upnvj.ac.id.

\section{BACKGROUND}

Circadian rhythms are psychological and biological cycles that show endogenous oscillation every 24 hours. This rhythm regulates various biological processes including sleep cycles in humans called "biological clocks" (Golombek and Rosenstein, 2010).

Circadian Rhythm Sleep Disorders (CRSD) is a sleep pattern disorder caused by changes in biological hours in humans. CRSD is a circadian rhythm disorder that occurs most often in adolescents and adults with a prevalence of $7 \%$ to $16 \%$ (Wichniak et al., 2017).

CRSD can cause various diseases such as cardiac arrhythmias, ischemic strokes, epilepsy, dementia and even Alzheimer's disease. (Brzecka et al., 2018; Smolensky et al., 2015).

CRSD disorders have also been reported to reduce concentration, increase the risk of neglect, insomnia, and other psychological disorders (Zee et al., 2013).

Nurse work in emergency department (ED) is a job that requires high concentra- 
tion, but the shift work system makes nurses very vulnerable to CRSD. This is very dangerous for the patient safety, so it needs a clearer understanding of CRSD and how to overcome it.

The purpose of this study is to review Circadian Rhythm Sleep Disorders due to work shifts and possible risks to the ED nurse and how to overcome the disorder.

SUBJECTS AND METHOD
This article was a systematic review
conducted by reviewing topics related to
CRSD published since 2000-2018 from
various databases including: PubMed, PMC
Central and Elsevier open-access.
The study was conducted from July 1
to 14, 2018 using the following keywords:
"Circadian Rhythm Sleep Disorders",
"treatment AND CRSD", "the effect of
CRSD", "CRSD AND nursing, and" CRSD in
night workers".
The criteria for the article under study
are: direct research conducted on adults
and workers who have night shifts,
systematic reviews, international reviews
and guidelines. After the search process, 20
articles will be reviewed.

\section{RESULTS \\ 1. Biological Clock and Circadian Rhythm}

Humans will adapt to day and night, dark and light because, temperature, light, and environmental changes will affect the body's metabolic system (Shea, 2011).

The adaptation process is done by resting, sleeping, and awakening. These three processes are regulated by an endogenous mechanism that lasts for 24 hours and continues to repeat so-called "Circadian rhythms". The center of circadian rhythm regulation is located in the central nervous system in the suprachiasmatic nucleus (SCN) called the main clock, but the whole process can occur in the liver, adipose tissue, and the digestive tract called peripheral clocks (Wichniak et al., 2017).

\section{The circadian rhythm mechanism is based on the light response}

Circadian rhythms are very dependent on light. This process begins when many retinal ganglion cells contain melanopsin as the main receptor for light giving photic information directly to the SCN (retinohypotalamic) and indirectly (retinogeniculate) (Burman, 2017). This response is used by SCN to regulate circadian rhythms which ultimately regulate the function of heart rhythm, autonomic function, endocrine system, and metabolism. It is in situations where light (exposure duration and spectrum length) is inadequate, rhythm signals for resting and even sleeping (Smith and Eastman, 2009).

Determination of the beginning and end of circadian rhythms is strongly influenced by light and melatonin excretion. During the night the pineal gland secrete melatonin 2-3 hours before one's regular sleep and will continue to decline until it reaches its lowest point at night and the next circadian rhythm begins, melatonin levels can be measured through plasma, urine and saliva (Bencloucif et al., 2008).

\section{The mechanism of circadian rhythms is based on genetic regulation}

Some gene experiments modulated by melatonin have been reported to affect circadian rhythms as Per 1 (homologous period 1), Per2 (homologous period 2), BMal1, and two cryptochrome (Cry) homologous genes (cryptochrome 1 gene, Cry1, and cryptochrome 2 genes, Cry2) (Takahashi et al., 2008).

These genes and their products interact to form the translation of the basic molecular feedback transcription of the 
circadian rhythm. During the day, the BMal1 gem interacts with the Cry gene to produce maximizing this transcription. Protein Per and Cry translate the results to the SCN nucleus and inhibit CLOCKY-BMAL1 transcription (Phyllis et al., 2013).

During the end of the night, the PerCry gene regulates the cycle for the next circadian stage to begin. An estimated 10\% of all genes in the body's expression process depend on the circadian rhythm gene (gem of the body clock), but the peripheral network has its own settings that are synchronized by the SCN direct message (Ko et al., 2006).

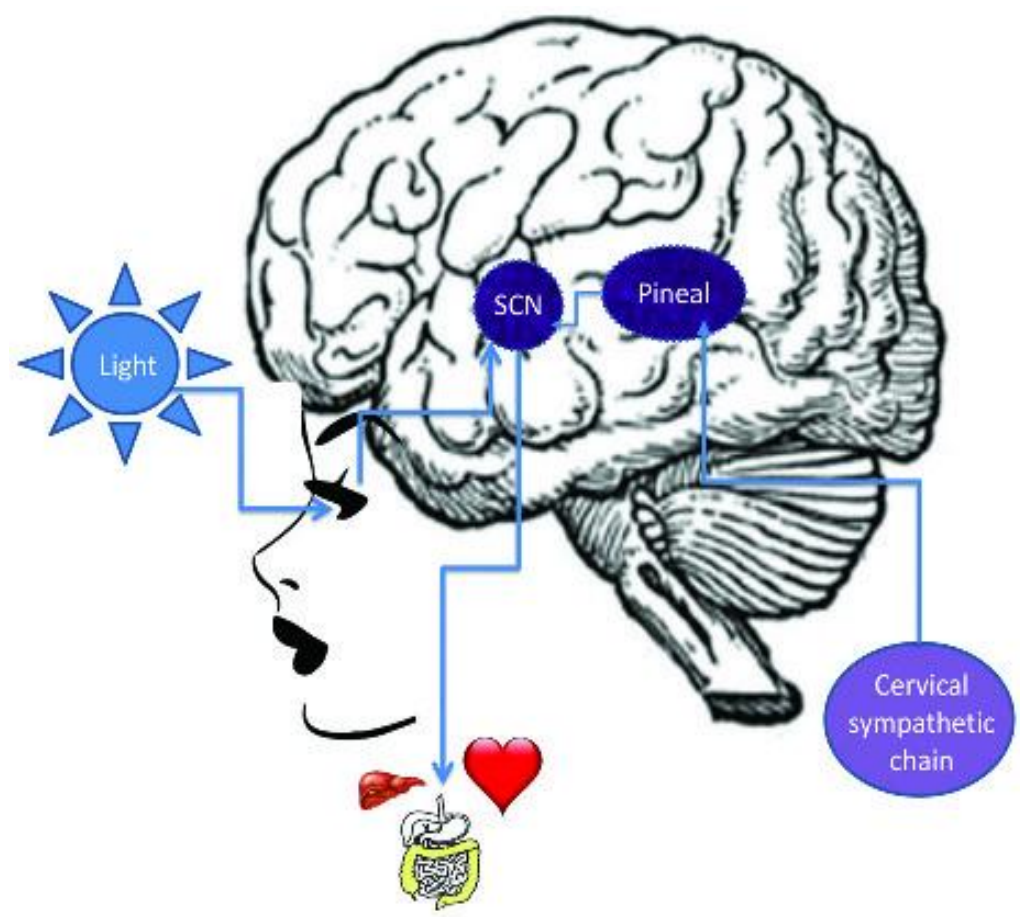

Figure 1. The mechanism of light in the regulation of circadian rhythms Sumber: Pavlova, 2017.

\section{Circadian Rhythm Sleep Disorders (CRSD)}

Based on International Classification of Sleep Disorders (ICSD), CRSWD diagnosis can be confirmed if there were three criteria as follows:

(1) Further sleep-wake rhythm disturbances which often called circadian rhythm sleep-wake disorders (CRSWD) occurred at least 1 month (chronic) due to changes in the endogenous circadian time system or misalignment between endogenous circadian rhythms and sleep-wake schedules needed by the physical, social environment, and an individual's employment.
(2) This circadian rhythm disturbance could lead to insomnia at night, excessive sleepiness in the morning or during the day or both.

(3) Sleep and wake disorders caused significant clinical, physical, social, occupational, educational, or other important mental disorders.

However, the classifications of sleepwake circadian rhythms (CRSWD) based on endogenous factors were delayed sleepwake phase disorder (DSWPD), advanced sleep-wake phase disorder (ASWPD), non24-hour sleep-wake rhythm disorder (N24SWRD), and irregular sleep-wake rhythm disorder (ISWRD). This endoge- 
nous disorder was caused by homeostatic changes in the body, changes in digestive functions such as changes in meal times, quantity of food, and composition. In addition, the interference could also be caused by exogenous factors, among others: Shift work disorder (SWD) caused by changes in sleep time due to work or school schedules that require staying awake at night or during regular rest periods, and jet lag disorder which was a disorder caused by significant time differences such as travel across the countries or continents (Wichniak et al., 2017).

Thus, CRSD was very likely to occur to nurses who would always get a night shift and must be awake all night.

In addition, CRSD could also be determined by measuring melatonin levels. In sufficient conditions of the light, the melatonin was secreted at 9:00 and 10:00 $\mathrm{pm}$ with the maximum level in the adult plasma by $60-70 p g / m l$ (reached at 2.00 and $4.00 \mathrm{am}$. Melatonin secretion substantially decreased at 7.00 and 9.00 am (Zawilska et al., 2009).

\section{DISCUSSIONS \\ 1. The Risk of CRSD and its Potensial Relationship with EI Nurse Negligence}

Untreated CRSD could lead to a variety of physical, psychological, and behavioral disorders (Phyllis et.al, 2013). Physical disorders that could occur include: rheumatoid arthritis, asthma, coronary heart disease, cardiac arrhythmias, hemorrhagic and ischemic strokes, epilepsy, headaches, gastric and duodenal ulcers, gastroesophageal reflux, and biliary colic (Silvertsen et al., 2017).

Previous research has reported that sleep disorders could be one of the symptoms and risk factors for Alzheimer's disease, insomnia, menstrual disorders in women, and dementia (Brzecka et al., 2018).

Emergency Installation (EI) was the patients' main access to the first treatment with various levels of emergency cases in the hospital (Emergency department, 2018). The EI was a room with overcrowded conditions, according to The College of Emergency Medicine (2012), this was affected by a variety of factors including the large number of health personnel from various multi-disciplines, variations in levels of gravity, high demands of the community, work stress, high workload, and the level of patients' dependence in nursing care.

If the condition was occurred for a long time, the nurse would get tired easily, depressed, and cannot handling the patient properly (Cole, 2011). According to Afleck et al. (2013), this over-crowded situation was one of the factors that worsened the quality of treatment given by the nurses to patients in the EI. This condition would adversely affect patients' safety, comfort, and satisfaction.

Nurses who used their night time to work and sleep at day time were more likely to experience CRSD and it can caused health problems such as increasing the risk of heart disease, gastrointestinal disorders, and chronic fatigue. This chronic fatigue was a severe fatigue in the body that would affect other diseases, reduced appetite, and also can reduce the nurses' motivation (Carole et al., 2008).

Previous study has reported that women were more likely to experience CRSD than men, with a ratio of 5.7 times for women and 3.7 times for men (McNeely et al., 2014).

2. CRSD Diagnosis due to Exogenous Work Shift Factor

Of the various types of CRSD caused by exogenous factors, night shift work was the 
most common reason stated by the subjects. Almost 20\% of professional workers experienced irregular night shifts and around 10-40\% experienced shift work disorders (Becker et al., 2015).

This diagnosis was confirmed if all these following criteria were found:

(1) Insomnia and/or excessive sleepiness along with a reduction in sleep time due to working with the shift system.

(2) Symptoms which continued to occur for at least three months with the work shift system.

(3) Sleep log and monitoring of actigraphy (if possible along with a measured light exposure test) of at least 14 days of working and holidays indicated sleep disorder.

Biological assessment such as: dim light melatonin onset (DLMO) was found in low levels of 6-sulfatoxymelatonin in urine (Morgenthaler et al., 2007).

\section{CRSD Management Guidelines due to Work Shifts}

Several steps and principles for CRSD handling due to work shifts according to Morgenthaler et al., (2007), among others:

(1) Sleeping for about 30 minutes before going to work after 6-7 hours of long sleep can be useful to reduce the risk of accidents at work, and significantly improved physical and psychological performance.

(2) Looking for a bright location in working time, because light could give a response to the $\mathrm{SCN}$ to keep people awake.

(3) After finishing the work at night, go home and darken or dim the lights to help people to sleep quickly, it would be better to wear dark glasses during the trip home in order to avoid adequate sunlight.
(4) The enhancement of sleep quality could also be done by giving a low dose of 0.5-3 mg of melatonin per day.

(5) Resetting the sleep schedule, for example, if the work was started before $10 \mathrm{pm}$ (for 8-hour shift) then people need to sleep at 7 am - 8 pm or 2 pm - 9 $\mathrm{pm}$, then wake up and try to get a short sleep (30 minutes before work).

(6) If it was required to take a higher dose of melatonin, which was 3-5 mg, it must be given 3 hours before the scheduled bedtime. During this particular time, bright light must be avoided.

\section{REFERENCES \\ Affleck A, Parks P, Drummond A, Rowe B, Howard J (2013).Emergency depart- ment overcrowding and access block, Canadian Associaton of Emergency Physicians CJEM. 15(6): 359-370.}

Becker T, Penzel T, Fietze I (2015). A new German Charite Jet Lag Scale for jet lag symptoms and application. Ergonomics, 58: 811-821.

Benloucif S, Burgess HJ, Klerman EB (2008). Measuring melatonin in humans. J Clin Sleep Med, 4(1): 6669.

Carole W, Carol Tavris (2008). Psikologi Edisi Kesembilan, jilid 1. Erlangga: Jakarta.

Cole JB (2011). Compassion Fatigue if The Nurse's Ability to Care is Affected, Quality of Care Could Suffer.

Brzecka A, Leszek J, Ashraf GM, Ejma M, Ávila-Rodriguez MF, Yarla NS, Tarasov VV, et al. (2018). Sleep Disorders Associated With Alzheimer Disease: A Perspective. Frontier in Neutrosciance. 12(1): 330.

Emergency department (2018). Available at: http://www.uhs.nhs.uk/OurServices/Emergencymedicine/Emer- 
gencyDepartment.aspx Accessed

August 2018.

Golombek DA, Rosenstein RE (2010). Physiology of circadian entrainment. Physiol Rev. 90(3):1063.

Ko CH, Takahashi JS (2006). Molecular components of the mammalian circadian clock. Hum Mol Genet. 15: R271-R277.

Morgenthaler TI, Lee-Chiong T, Alessi C, Friedman L, Aurora RN, Boehlecke B (2007). Practice parameters for the clinical evaluation and treatment of circadian rhythm sleep disorders. An American Academy of Sleep Medicine report. 30: 1445-1459.

Phyllis CZ, Attarian H, Videnovic A (2013). Circadian Rhythm Abnormalities. Continuum. American Academy of Neurology.

Sivertsen B, Harvey AG, Pallesen S, Hysing $M$ (2015). Mental health problems in adolescents with delayed sleep phase: Results from a large population-based study in Norway. J. 24: 11-18.

Shea SA, Hilton MF, Hu K, Scheer FAJL (2011). Existence of an endogenous circadian blood pressure rhythm in humans that peaks in the evening. Circ Res. 108(8): 980-984.

Smith MR, Revell VL, Eastman CI (2009). Phase Delaying the Human Circadian Clock with Blue-Enriched Polychromatic Light. Sleep Med. 10(3): 287294.
Smolensky MH, Portaluppi F, Manfredini R, Hermida RC, Tiseo R, SackettLundeen LL, et al. (2015). Diurnal and twenty-four hour patterning of human diseases: cardiac, vascular, and respiratory diseases, conditions, and syndromes. Sleep Med. Rev. 21: 3-11.

Takahashi JS, Hong HK, Ko CH, McDearmon EL (2008). The genetics of mammalian circadian order and disorder: implications for physiology and disease. Nat Rev Genet. 9(10): 764-775.

The College Of Emergency Medicine. (2012). Crowding in emergency departments. Revised Edition.

Wichniak A, Jankowski KS, Skalski M, Skwarło-Sońta K, Zawilska ZB, Żarowski M, et al. (2017). Treatment guidelines for Circadian Rhythm Sleep - Wake Disorders of the Polish Sleep Research Society and the Section of Biological Psychiatry of the Polish Psychiatric Association. Part II. Diagnosis and treatment. Psychiatr. Pol. 51(5): 815-832.

Zawilska JB, Skene DJ, Arendt J (2009). Physiology and pharmacology of melatonin in relation to biological rhythms. Pharmacol. Rep. 61(3): 383-410.

Zee PC, Vitiello MV. (2009). Circadian rhythm sleep disorder: irregular sleep wake rhythm type. Sleep Med Clin. 4(2):213Y218. 